\title{
Volume of Distribution Predicted Normalized by Surface Area
}

National Cancer Institute

\section{Source}

National Cancer Institute. Volume of Distribution Predicted Normalized by Surface Area. NCl Thesaurus. Code C92426.

The predicted volume of distribution associated with the terminal slope following intravascular administration divided by the surface area. 